\title{
The effects of MAPK inhibitors on antimycin A-treated calf pulmonary arterial endothelial cells in relation to cell death, reactive oxygen species and glutathione
}

\author{
YONG HWAN HAN, BO RA YOU, HWA JIN MOON, SUNG ZOO KIM, SUHN HEE KIM and WOO HYUN PARK
}

\author{
Department of Physiology, Medical School, Centers for Healthcare Technology Development, \\ Institute for Medical Sciences, Chonbuk National University, JeonJu 561-180, Republic of Korea
}

Received August 28, 2009; November 2, 2009

DOI: 10.3892/mmr_00000234

\begin{abstract}
Antimycin A (AMA) inhibits succinate oxidase and the mitochondrial electron transport chain between cytochrome $\mathrm{b}$ and $\mathrm{c}$. Here, we report on the effects of mitogen-activated protein kinase (MAPK) inhibitors on AMA-treated calf pulmonary artery endothelial cells (CPAEC) in relation to cell death, reactive oxygen species (ROS) and glutathione (GSH). AMA inhibited the growth of CPAEC and also induced cell death, which was accompanied by the loss of mitochondrial membrane potential (MMP; $\Delta \Psi_{\mathrm{m}}$ ). AMA increased ROS levels including $\mathrm{O}_{2}{ }^{--}$, and depleted GSH cell numbers in CPAEC. All the MAPK (MEK, JNK, p38) inhibitors enhanced cell growth inhibition and death by AMA, and appeared to augment ROS but not $\mathrm{O}_{2}{ }^{-}$ levels in AMA-treated CPAEC. MEK and p38 inhibitors did not increase the number of GSH-depleted cells in AMA-treated CPAEC, but JNK inhibitor significantly did. Each MAPK inhibitor affected cell growth, death, ROS and GSH levels differently in comparison to control CPAEC. In conclusion, the MAPK inhibitors enhanced cell growth inhibition and death by AMA. Changes in ROS and GSH levels by AMA and/or MAPK inhibitors affected growth and death in CPAEC.
\end{abstract}

Correspondence to: Dr Woo Hyun Park, Department of Physiology, Medical School, Chonbuk National University, JeonJu 561-180, Republic of Korea

E-mail: parkwh71@chonbuk.ac.kr

Abbreviations: AMA, antimycin A; CMFDA, 5-chloromethylfluorescein diacetate; CPAEC, calf pulmonary arterial endothelial cells; DHE, dihydroethidium; EC, endothelial cells; ERK, extracellular signal-regulated kinase; FBS, fetal bovine serum; FITC, fluorescein isothiocyanate; GSH, glutathione; $\mathrm{H}_{2}$ DCFDA, 2',7'-dichlorodihydrofluorescein diacetate; JNK, c-Jun N-terminal kinase; MAPK, mitogen-activated protein kinase; MEK, MAP kinase or ERK kinase; MMP $\left(\Delta \Psi_{\mathrm{m}}\right)$, mitochondrial membrane potential; MTT,3-(4,5-dimethylthiazol-2-yl)-2,5-diphenyltetrazolium bromide; PI, propidium iodide; ROS, reactive oxygen species

Key words: antimycin A, apoptosis, calf pulmonary arterial endothelial cells, mitogen-activated protein kinase inhibitor, reactive oxygen species, glutathione

\section{Introduction}

Antimycin A (AMA) is a product predominantly composed of antimycin A1 and A3, which are derived from Streptomyces kitazawensis (1). AMA inhibits succinate oxidase and NADH oxidase, and also inhibits the mitochondrial electron transport chain between cytochrome $b$ and $c(2,3)$. The inhibition of electron transport causes a collapse of the proton gradient across the mitochondrial inner membrane, thereby breaking down mitochondrial membrane potential (MMP; $\Delta \Psi_{\mathrm{m}}$ ) (4). This inhibition also results in the production of reactive oxygen species (ROS) (5). Cells possess antioxidant systems to control the redox state, which is important for their survival. Excessive production of ROS gives rise to the activation of events leading to cell death in several cell types $(6,7)$. Evidence indicates that either the presence of ROS or the collapse of $\operatorname{MMP}\left(\Delta \Psi_{\mathrm{m}}\right)$ opens the mitochondrial permeability transition pore, which is accompanied by the release of proapoptotic molecules such as cytochrome c into the cytoplasm (8). Since AMA acts directly on the mitochondria, AMA-induced apoptosis has been reported in many experiments, including our report on As4.1 Juxtaglomerular cells and lung cancer cells $(9-13)$.

Mitogen-activated protein kinases (MAPKs) are a large family of serine/threonine kinases that are major components of the signaling pathways involved in cell proliferation, differentiation and death (14). There are currently four known MAPKs: extracellular signal regulated kinase (ERK1/2), c-Jun N-terminal kinase/stress-activated protein kinase (JNK/ SAPK), and p38 (15). Each MAPK pathway has relatively different upstream activators and specific substrates (16). Numerous lines of evidence demonstrate that JNK and p38 are strongly activated by ROS or by a mild oxidative shift in the intracellular thiol/disulfide redox state, leading to apoptosis $(17,18)$. ROS are also known to induce ERK phosphorylation and to activate the ERK pathway (19). In most instances, ERK activation has a pro-survival function rather than pro-apoptotic effects (20).

The vascular endothelium is involved in various regulatory roles, including blood pressure, inflammation and angiogenesis (21). Fundamental to the transition of tumors from a latent to a malignant state is angiogenesis involving the 
formation of new blood vessels from pre-existing vasculature. The proliferation of endothelial cells (ECs; sprouting) is the early step of angiogenesis. Despite the critical role played by vascular ECs in tumor biogenesis and progression, the effects of mitochondria inhibitors, in particular AMA, on ECs remain relatively poorly understood.

In the present study, we demonstrated that AMA inhibits the growth of calf pulmonary artery endothelial cells (CPAEC) and investigated the effects of MAPK inhibitors on AMA-treated CPAEC in relation to cell death, ROS and glutathione (GSH).

\section{Materials and methods}

Cell culture. CPAEC were obtained from the Korean Cell Line Bank and were maintained in a humidified incubator containing $5 \% \mathrm{CO}_{2}$ at $37^{\circ} \mathrm{C}$. The cells were cultured in RPMI1640 supplemented with $10 \%$ fetal bovine serum (FBS) and $1 \%$ penicillin-streptomycin (Gibco Brl, Grand Island, NY, USA), and were routinely grown in $100-\mathrm{mm}$ plastic tissue culture dishes (Nunc, Roskilde, Denmark) and harvested with a solution of trypsin-EDTA (Gibco Brl) while in the logarithmic phase of growth. Cell culture conditions were identical for all experiments.

Reagents. AMA was purchased from Sigma-Aldrich Chemical Company (St. Louis, MO, USA) and dissolved in ethanol at $20 \mathrm{mM}$ as a stock solution. JNK inhibitor (SP600125), MEK inhibitor (PD98059) and p38 inhibitor (SB203580) were purchased from Calbiochem (San Diego, CA, USA). All the reagents were dissolved in DMSO at $10 \mathrm{mM}$ as a stock solution. Cells were pre-treated with each MAPK inhibitor for 30 min prior to treatment with AMA. Based on previous experiments, $100 \mu \mathrm{M}$ AMA was chosen as a suitable dose to differentiate the levels of cell growth inhibition or death in the presence or absence of each MAPK inhibitor. A dose of $10 \mu \mathrm{M}$ of each MAPK inhibitor was applied as the optimal dose in this experiment. DMSO (0.4\%) and ethanol $(0.4 \%)$ were used as the control vehicles. Stock solutions were wrapped in foil and maintained at $-20^{\circ} \mathrm{C}$.

Cell growth assay. The effect of the drugs on CPAEC growth was determined by measuring the 3-(4,5-dimethylthiazol-2-yl)2,5-diphenyltetrazolium bromide (MTT) dye absorbance of living cells as previously described (22). In brief, 3x10 4 cells/ well were seeded in 96-well microtiter plates (Nunc). After exposure to $100 \mu \mathrm{M}$ AMA with or without $10 \mu \mathrm{M} \mathrm{JNK}$, MEK or p38 inhibitor for $24 \mathrm{~h}, 20 \mu \mathrm{l}$ of MTT (Sigma) solution (2 mg/ $\mathrm{ml}$ in PBS) was added to each well of 96 -well plates. The plates were incubated for an additional $4 \mathrm{~h}$ at $37^{\circ} \mathrm{C}$. MTT solution in the medium was aspirated off and $200 \mu \mathrm{l}$ of DMSO was added to each well to solubilize the formazan crystals formed in viable cells. Optical density was measured at $570 \mathrm{~nm}$ using a microplate reader (Spectra MAX 340; Molecular Devices Co., Sunnyvale, CA, USA).

Sub-G1 cell analysis. Sub-G1 cells were determined by propidium iodide $(\mathrm{PI})(\mathrm{Ex} / \mathrm{Em}=488 \mathrm{~nm} / 617 \mathrm{~nm}$ ) (SigmaAldrich) staining as previously described (23). In brief, $1 \times 10^{6}$ cells in a $60 \mathrm{~mm}$ culture dish (Nunc) were incubated with
$100 \mu \mathrm{M}$ AMA with or without $10 \mu \mathrm{M}$ MEK, JNK or p38 inhibitor for $24 \mathrm{~h}$, then washed with PBS and fixed in $70 \%$ ethanol. Subsequetly, the cells were washed again with PBS, then incubated with PI $(10 \mu \mathrm{g} / \mathrm{ml})$ with simultaneous RNase treatment at $37^{\circ} \mathrm{C}$ for $30 \mathrm{~min}$. Cell DNA content was measured using a FACStar flow cytometer (Becton Dickinson, San Jose, CA, USA) and analyzed using lysis II and CellFIT software (Becton Dickinson) or ModFit software (Verity Software House, Inc., ME, USA).

Annexin $V$ staining. Apoptosis was determined by staining cells with annexin V-fluorescein isothiocyanate (FITC) (Ex/ $\mathrm{Em}=488 \mathrm{~nm} / 519 \mathrm{~nm}$ ) as previously described (24). In brief, $1 \times 10^{6}$ cells in a $60 \mathrm{~mm}$ culture dish were incubated with $100 \mu \mathrm{M}$ AMA with or without $10 \mu \mathrm{M}$ JNK, MEK or p38 inhibitor for $24 \mathrm{~h}$. Cells were washed twice with cold PBS and then resuspended in $500 \mu \mathrm{l}$ of binding buffer $(10 \mathrm{mM}$ HEPES/NaOH pH 7.4, $140 \mathrm{mM} \mathrm{NaCl}, 2.5 \mathrm{mM} \mathrm{CaCl}_{2}$ ) at a concentration of $1 \times 10^{6}$ cells $/ \mathrm{ml}$. Annexin V-FITC (5 $\left.\mu \mathrm{l}\right)$ (Pharmingen, San Diego, CA, USA) was then added to these cells, which were analyzed with a FACStar flow cytometer (Becton Dickinson).

Measurement of MMP $\left(\Delta \Psi_{m}\right)$. MMP $\left(\Delta \Psi_{\mathrm{m}}\right)$ levels were measured using Rhodamine 123 fluorescent dye (Ex/ Em=485 nm/535 nm) as previously described (25). In brief, $1 \times 10^{6}$ cells in a $60 \mathrm{~mm}$ culture dish were incubated with $100 \mu \mathrm{M}$ AMA with or without $10 \mu \mathrm{M}$ JNK, MEK or p38 inhibitor for $24 \mathrm{~h}$. Cells were washed twice with PBS and incubated with Rhodamine $123(0.1 \mu \mathrm{g} / \mathrm{ml})$ (Sigma) at $37^{\circ} \mathrm{C}$ for $30 \mathrm{~min}$. Rhodamine 123 staining intensity was determined by a FACStar flow cytometer (Becton Dickinson). Negative staining for Rhodamine 123 indicated the loss of $\operatorname{MMP}\left(\Delta \Psi_{\mathrm{m}}\right)$ in CPAEC. MMP $\left(\Delta \Psi_{\mathrm{m}}\right)$ levels in cells not including MMP $\left(\Delta \Psi_{\mathrm{m}}\right)$ loss cells were expressed as the mean fluorescence intensity (MFI), calculated by CellQuest software.

Detection of intracellular $\mathrm{ROS}$ and $\mathrm{O}_{2}^{-*}$ levels. Intracellular ROS, such as $\mathrm{H}_{2} \mathrm{O}_{2}$, ${ }^{\circ} \mathrm{OH}$ and $\mathrm{ONOO}$; was detected by means of an oxidation-sensitive fluorescent probe dye, 2',7'-dichlorodihydrofluorescein diacetate $\left(\mathrm{H}_{2} \mathrm{DCFDA}\right)(\mathrm{Ex} /$ $\mathrm{Em}=495 \mathrm{~nm} / 529 \mathrm{~nm}$ ) (Invitrogen Molecular Probes, Eugene, OR, USA) (26). $\mathrm{H}_{2}$ DCFDA is poorly selective for $\mathrm{O}_{2}{ }^{\circ}$. By contrast, dihydroethidium (DHE) $(\mathrm{Ex} / \mathrm{Em}=518 \mathrm{~nm} / 605 \mathrm{~nm})$ (Invitrogen Molecular Probes) is highly selective for $\mathrm{O}_{2}{ }^{-}$ among ROS. In brief, $1 \times 10^{6}$ cells in a $60 \mathrm{~mm}$ culture dish were incubated with $100 \mu \mathrm{M}$ AMA with or without $10 \mu \mathrm{M}$ JNK, MEK or p38 inhibitor for $24 \mathrm{~h}$. Cells were then washed in PBS and incubated with $20 \mu \mathrm{M} \mathrm{H}_{2}$ DCFDA or DHE at $37^{\circ} \mathrm{C}$ for $30 \mathrm{~min}$ according to the manufacturer's instructions. DCF and DHE fluorescence was detected using a FACStar flow cytometer (Becton Dickinson). ROS and $\mathrm{O}_{2}{ }^{--}$levels were expressed as the MFI, calculated by CellQuest software.

Detection of intracellular glutathione. Cellular GSH levels were analyzed using 5-chloromethylfluorescein diacetate (CMFDA) (Ex/Em=522 nm/595 nm) (Molecular Probes) as previously described (26). In brief, $1 \times 10^{6}$ cells in a $60 \mathrm{~mm}$ culture dish were incubated with $100 \mu \mathrm{M}$ AMA with or without $10 \mu \mathrm{M}$ JNK, MEK or p38 inhibitor for $24 \mathrm{~h}$. Cells were then 
washed with PBS and incubated with $5 \mu \mathrm{M}$ CMFDA at $37^{\circ} \mathrm{C}$ for $30 \mathrm{~min}$. CMF fluorescence intensity was determined using a FACStar flow cytometer (Becton Dickinson). Cells negative for CMF staining (GSH-depleted cells) were expressed as the percent of (-) CMF cells. CMF levels in cells not including GSH-depleted cells were expressed as the MFI, calculated by CellQuest software.

Statistical analysis. The results shown in the figures represent the mean of at least three independent experiments (bar, SD). Data were analyzed using Instat software (GraphPad Prism4, San Diego, CA, USA). The Student's t-test or one-way analysis of variance (ANOVA) with post hoc analysis using Tukey's multiple comparison test were applied for parametric data. Statistical significance was defined as $\mathrm{p}<0.05$.

\section{Results}

Effect of MAPK inhibitors on cell growth and death in $A M A$-treated CPAEC. The effect of MAPK inhibitors on the growth of AMA-treated CPAEC was examined using the MTT assay. Treatment with $100 \mu \mathrm{M}$ AMA inhibited the growth of CPAEC by $~ 50 \%$ at $24 \mathrm{~h}$ (Fig. 1A). All the MAPK inhibitors enhanced growth inhibition by AMA, with JNK inhibitor showing a strong effect (Fig. 1A). All the inhibitors reduced the growth of control CPAEC (Fig. 1A).

Treatment with AMA increased sub-G1 cell numbers in CPAEC by $\sim 16 \%$ compared with AMA-untreated control CPAEC, and all the MAPK inhibitors magnified sub-G1 cell numbers in AMA-treated CPAEC (Fig. 1B). In addition, AMA increased the number of annexin V-stained cells in the CPAEC, indirectly implying that CPAEC death by AMA occurred via apoptosis (Fig. 1C). All the MAPK inhibitors increased annexin V-FITC-positive cell numbers in AMA-treated CPAEC (Fig. 1C). JNK inhibitor alone increased annexin V-FITC-positive cells in control CPAEC (Fig. 1C).

Effect of MAPK inhibitors on MMP $\left(\Delta \Psi_{m}\right)$ in AMA-treated $C P A E C$. Apoptosis is closely related to the collapse of MMP $\left(\triangle \Psi_{\mathrm{m}}\right)(27)$. Thus, the loss of MMP $\left(\Delta \Psi_{\mathrm{m}}\right)$ in AMA-treated CPAEC was determined using Rhodamine 123 dye at $24 \mathrm{~h}$. As expected, the loss of MMP $\left(\Delta \Psi_{\mathrm{m}}\right)$ was observed in AMA-treated cells (Fig. 2A). The MEK and JNK inhibitors each slightly increased the loss of $\operatorname{MMP}\left(\Delta \Psi_{\mathrm{m}}\right)$ in AMA-treated CPAEC (Fig. 2A). p38 inhibitor did not affect MMP $\left(\Delta \Psi_{\mathrm{m}}\right)$ loss (Fig. 2A). JNK inhibitor alone triggered MMP $\left(\Delta \Psi_{\mathrm{m}}\right)$ loss in control CPAEC (Fig. 2A). AMA reduced MMP $\left(\Delta \Psi_{\mathrm{m}}\right)$ levels in the CPAEC not including Rhodamine 123-negative cells (Fig. 2B). None of the MAPK inhibitors significantly altered MMP $\left(\Delta \Psi_{\mathrm{m}}\right)$ levels in AMA-treated CPAEC (Fig. 2B). MMP $\left(\Delta \Psi_{\mathrm{m}}\right)$ levels in AMA-untreated control CAPEC were reduced by the MEK and JNK inhibitors, but were increased by p38 inhibitor (Fig. 2B).

Effect of MAPK inhibitors on $\mathrm{ROS}$ and $\mathrm{O}_{2}^{*}$ levels in AMA-treated CPAEC. Changes in intracellular ROS levels in CPAEC treated with AMA and/or each MAPK inhibitor were assessed. As shown in Fig. 3A, ROS (DCF) levels such as $\mathrm{H}_{2} \mathrm{O}_{2}$ were significantly increased in CPAEC treated with
A

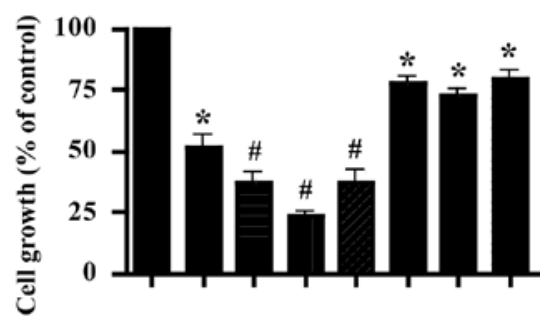

B

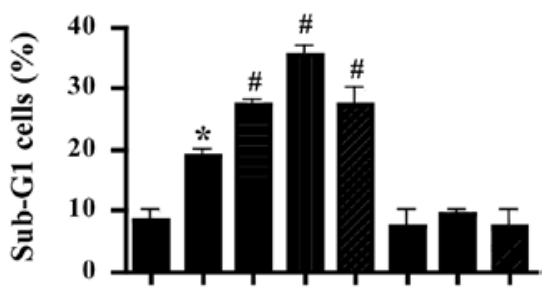

C

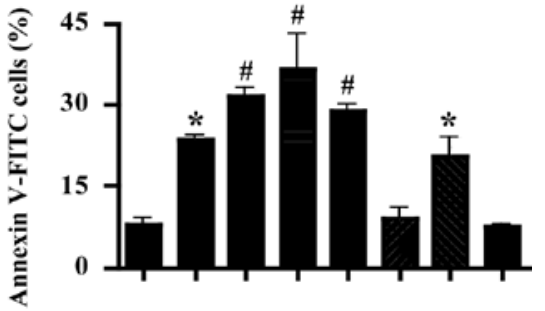

AMA $100 \mu \mathrm{M}:-++++--$

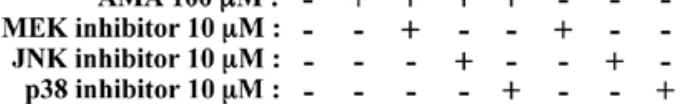

Figure 1. Effect of MAPK inhibitors on cell growth and death in AMA-treated CPAEC. Exponentially-growing CPAEC were treated with AMA for $24 \mathrm{~h}$ following a 30-min pre-incubation with each MAPK inhibitor. (A) CPAEC growth assessed by the MTT assay. (B and C) Percent of (B) sub-G1 and (C) annexin V-stained cells measured using a FACStar flow cytometer. ${ }^{*} \mathrm{P}<0.05$ compared with the control group. ${ }^{\#} \mathrm{P}<0.05$ compared with cells treated with AMA only.

AMA at $24 \mathrm{~h}$. All the MAPK inhibitors appeared to augment ROS in AMA-treated CPAEC. This augmentation was significant with p38 inhibitor (Fig. 3A). All the MAPK inhibitors increased ROS levels in control CPAEC (Fig. 3A). When detecting intracellular $\mathrm{O}_{2}^{--}$levels in AMA-treated CPAEC, red fluorescence derived from DHE reflecting intracellular $\mathrm{O}_{2}{ }^{--}$levels was increased at $24 \mathrm{~h}$ (Fig. 3B). None of the MAPK inhibitors significantly affected $\mathrm{O}_{2}^{-*}$ levels in AMA-treated CPAEC (Fig. 3B). The MEK and JNK inhibitors increased $\mathrm{O}_{2}{ }^{-*}$ levels in control CPAEC (Fig. 3B).

Effect of MAPK inhibitors on GSH levels in AMA-treated $C P A E C$. When analyzing changes in GSH levels in CPAEC using CMF fluorescence dye at $24 \mathrm{~h}$, the number of GSH-depleted cells was observed to increase by $\sim 17 \%$ in AMA-treated CPAEC compared with AMA-untreated control CPAEC (Fig. 4A). The MEK and p38 inhibitors did not increase the number of GSH-depleted cells in AMA-treated CPAEC (Fig. 4A). However, JNK inhibitor significantly increased GSH-depleted cells in both AMA-treated and -untreated CPAEC (Fig. 4A). Furthermore, when CMF (GSH) levels in 
A

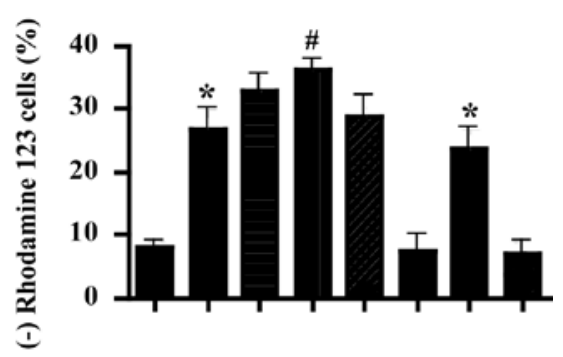

B

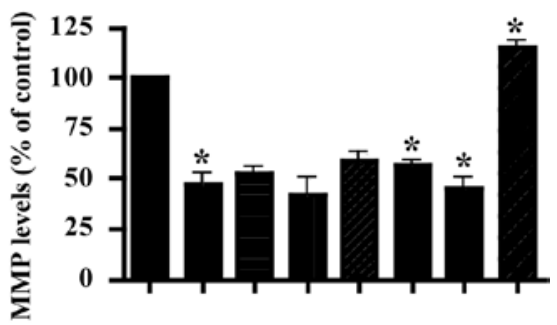

AMA $100 \mu \mathrm{M}:-++++-\quad-$

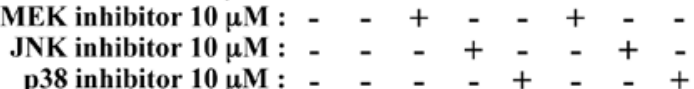

Figure 2. Effect of MAPK inhibitors on MMP $\left(\Delta \Psi_{\mathrm{m}}\right)$ in AMA-treated CPAEC. Exponentially-growing CPAEC were treated with AMA for $24 \mathrm{~h}$ following a 30-min pre-incubation with each MAPK inhibitor. MMP $\left(\Delta \Psi_{\mathrm{m}}\right)$ in CPAEC was measured with a FACStar flow cytometer. (A and B) Percent of (A) Rhodamine 123-negative [MMP $\left(\Delta \Psi_{\mathrm{m}}\right)$ loss] cells and (B) $\operatorname{MMP}\left(\Delta \Psi_{\mathrm{m}}\right)$ levels compared with control CPAEC. ${ }^{\mathrm{P}}<0.05$ compared with the control group. ${ }^{\#} \mathrm{P}<0.05$ compared with cells treated with AMA only.

A

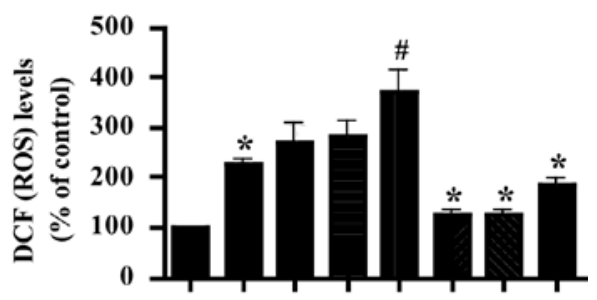

B

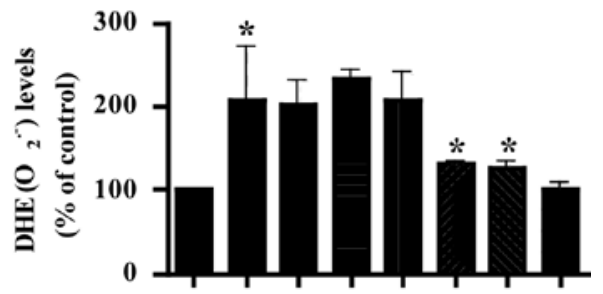

AMA $100 \mu \mathrm{M}:-\quad++++-\quad-$

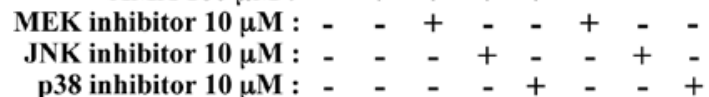

Figure 3. Effect of MAPK inhibitors on ROS levels in AMA-treated CPAEC. Exponentially-growing CPAEC were treated with AMA for $24 \mathrm{~h}$ following a 30-min pre-incubation with each MAPK inhibitor. ROS levels in CPAEC were measured using a FACStar flow cytometer. (A) DCF (ROS) and (B) DHE $\left(\mathrm{O}_{2}^{*}\right)$ levels $(\%)$ compared with control CPAEC. ${ }^{*} \mathrm{P}<0.05$ compared with the control group. ${ }^{*} \mathrm{P}<0.05$ compared with cells treated with AMA only.
A

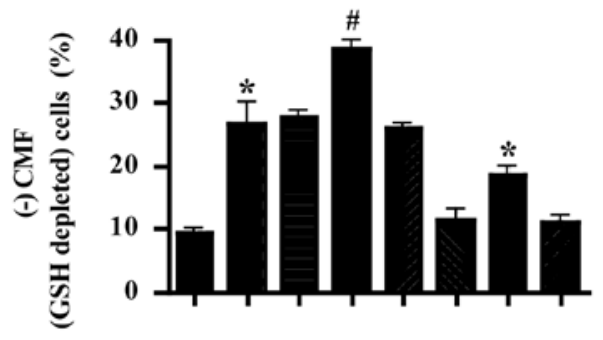

B

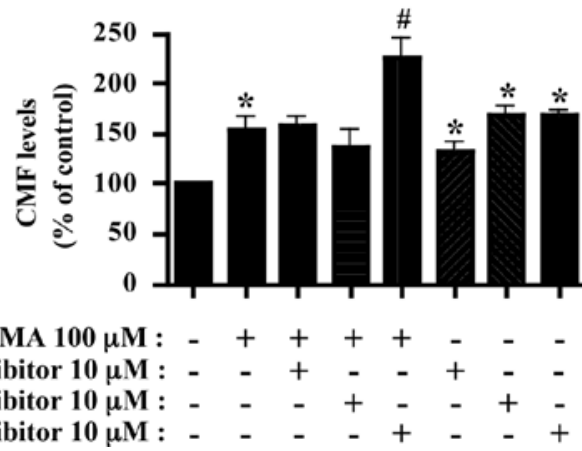

Figure 4. Effect of MAPK inhibitors on GSH levels in AMA-treated CPAEC. Exponentially-growing CPAEC were treated with AMA for $24 \mathrm{~h}$ following a 30-min pre-incubation with each MAPK inhibitor. GSH levels in CPAEC were measured using a FACStar flow cytometer. (A and B) Percent of (A) (-) CMF (GSH depleted) cells and (B) mean CMF (GSH) levels compared with control CPAEC. ${ }^{*} \mathrm{P}<0.05$ compared with the control group. ${ }^{*} \mathrm{P}<0.05$ compared with cells treated with AMA only.

CPAEC not including CMF-negative cells were assessed, the GSH level was increased in AMA-treated CPAEC (Fig. 4B). GSH levels in AMA-treated CPAEC were not affected by the MEK and JNK inhibitors, but were increased by p38 inhibitor (Fig. 4B). All the MAPK inhibitors increased GSH levels in control CPAEC (Fig. 4B).

\section{Discussion}

The present study focused on evaluating the effects of MAPK inhibitors on AMA-treated CPAEC in relation to cell death, ROS and GSH, since AMA inhibits the growth and induces the death of CPAEC. ERK activation has a pro-survival function rather than pro-apoptotic effects (20). Our results indicate that MEK inhibitor, which presumably inactivates ERK, increased the number of sub-G1 and annexin V-FITC-positive cells in AMA-treated CPAEC. This suggests that the inactivation of ERK by MEK inhibitor serves as an enhancing factor in AMA-induced CPAEC death. It is known that JNK and p38 lead to apoptosis $(17,18)$. According to our data, the JNK and p38 inhibitors increased cell death in AMA-treated CPAEC. These data suggest that JNK and p38 signal transduction negatively affects CPAEC death by AMA. In particular, JNK inhibitor alone increased the number of annexin V-FITCpositive cells in control CPAEC, implying that the prevention of JNK signaling by its inhibitor was closely related to CPAEC death. Moreover, all the MAPK inhibitors intensified growth inhibition in AMA-treated CPAEC, and also inhibited the 
growth of control CPAEC. These data suggest that the MAPK signaling pathways are positively involved in AMA-treated or -untreated CPAEC growth.

AMA disturbs the natural oxidation/reduction equilibrium in cells by causing a breakdown in MMP $\left(\Delta \Psi_{\mathrm{m}}\right)$ (4). Correspondingly, in CPAEC, AMA induced apoptosis via the loss of MMP $\left(\Delta \Psi_{\mathrm{m}}\right)$. Similar to the results regarding sub-G1 and annexin V-FITC-positive cells, the MEK and JNK inhibitors each slightly increased the loss of $\operatorname{MMP}\left(\Delta \Psi_{\mathrm{m}}\right)$ in AMA-treated CPAEC. However, p38 inhibitor did not increase MMP $\left(\Delta \Psi_{\mathrm{m}}\right)$ loss, which indicates that p38 signaling inhibition is not related to the loss pathway of MMP $\left(\Delta \Psi_{\mathrm{m}}\right)$ in AMA-treated CPAEC. JNK inhibitor increased the loss of MMP $\left(\Delta \Psi_{\mathrm{m}}\right)$ in AMA-untreated CPAEC, suggesting that JNK signaling is involved in the intact maintenance of $\operatorname{MMP}\left(\Delta \Psi_{\mathrm{m}}\right)$ in CPAEC. AMA reduced MMP $\left(\Delta \Psi_{\mathrm{m}}\right)$ levels in CPAEC. None of the MAPK inhibitors significantly altered MMP $\left(\Delta \Psi_{\mathrm{m}}\right)$ levels in AMA-treated CPAEC. MMP $\left(\Delta \Psi_{\mathrm{m}}\right)$ levels in AMA-untreated control CAPEC were reduced by the MEK and JNK inhibitors, but were increased by $\mathrm{p} 38$ inhibitor. These results suggest that MAPK signaling affects MMP $\left(\Delta \Psi_{\mathrm{m}}\right)$ levels in CPAEC differently depending on the co-incubation agents.

Increased intracellular ROS was reported to play an important role in AMA-induced cell death in liver (28) and A549 human lung cancer (5) cells. Likewise, in the present study, ROS levels including $\mathrm{O}_{2}{ }^{--}$were increased in AMA-treated CPAEC. All the MAPK inhibitors were observed to augment ROS levels in AMA-treated CPAEC, with p38 inhibitor showing a strong affect. However, none of the MAPK inhibitors increased $\mathrm{O}_{2}^{--}$levels in AMA-treated CPAEC. In AMA-untreated CPAEC, MEK inhibitor increased ROS levels including $\mathrm{O}_{2}{ }^{-}$and p38 inhibitor increased ROS (DCF) levels, both without inducing cell death. JNK inhibitor increased ROS levels including $\mathrm{O}_{2}{ }^{--}$in AMA-untreated control CPAEC, also triggering cell death and the loss of MMP $\left(\Delta \Psi_{\mathrm{m}}\right)$. These results suggest that CPAEC death by AMA and/or each MAPK inhibitor was not closely, but was at least partially, related to the level of ROS, and that MAPK inhibitors affect ROS levels in CPAEC differently depending on the co-treatment drugs.

$\mathrm{GSH}$, one of the main non-protein antioxidants in cells, provides electrons for enzymes such as glutathione peroxidase, which reduces $\mathrm{H}_{2} \mathrm{O}_{2}$ to $\mathrm{H}_{2} \mathrm{O}$ (29). According to our data, AMA increased the number of GSH-depleted cells in CPAEC. JNK inhibitor augmented the number of GSH-depleted cells in AMA-treated and -untreated CPAEC. These results appear to be correlated with the results of annexin V-FITC staining in CPAEC treated with AMA and/or JNK inhibitor. Our current findings support the notion that intracellular GSH content has a decisive effect on anticancer drug-induced apoptosis (30), but is not sufficient for the correct prediction of cell death, since the MEK and p38 inhibitors did not enhance the number of GSH-depleted cells in AMA-treated CPAEC. It is worth noting that the CMF (GSH) level in AMA-treated CPAEC was increased. This increase in GSH level likely occurred in response to the increase in ROS induced by AMA treatment, leading CPAEC that had reached their capacity to resist ROS insult to undergo cell death. In addition, all the MAPK inhibitors increased GSH levels in control CPAEC. Increased GSH levels also appeared to reduce increases in ROS effected by each MAPK inhibitor.
In conclusion, AMA induces apoptosis via the loss of $\operatorname{MMP}\left(\Delta \Psi_{\mathrm{m}}\right)$ in CPAEC, accompanied by an increase in ROS and GSH depletion. The MAPK inhibitors studied intensify cell growth inhibition and death by AMA. Changes in ROS and GSH by AMA and/or MAPK inhibitors affect cell growth and death in CPAEC.

\section{Acknowledgements}

This study was supported by a grant of the Korea Healthcare Technology R\&D Project, Ministry for Health, Welfare and Family Affairs of the Republic of Korea (A084194), and by a Korea Research Foundation Grant funded by the Government of the Republic of Korea (MOEHRD).

\section{References}

1. Nakayama K, Okamoto F and Harada Y: Antimycin A: isolation from a new Streptomyces and activity against rice plant blast fungi. J Antibiot 9: 63-66, 1956.

2. Maguire JJ, Kagan VE and Packer L: Electron transport between cytochrome $\mathrm{c}$ and alpha tocopherol. Biochem Biophys Res Commun 188: 190-197, 1992.

3. Alexandre A and Lehninger AL: Bypasses of the antimycin a block of mitochondrial electron transport in relation to ubisemiquinone function. Biochim Biophys Acta 767: 120-129, 1984.

4. Campo ML, Kinnally KW and Tedeschi H: The effect of antimycin A on mouse liver inner mitochondrial membrane channel activity. J Biol Chem 267: 8123-8127, 1992.

5. Panduri V, Weitzman SA, Chandel NS and Kamp DW: Mitochondrial-derived free radicals mediate asbestos-induced alveolar epithelial cell apoptosis. Am J Physiol Lung Cell Mol Physiol 286: L1220-L1227, 2004.

6. Wallach-Dayan SB, Izbicki G, Cohen PY, Gerstl-Golan R, Fine A and Breuer R: Bleomycin initiates apoptosis of lung epithelial cells by ROS but not by Fas/FasL pathway. Am J Physiol Lung Cell Mol Physiol 290: L790-L796, 2006.

7. Simon HU, Haj-Yehia A and Levi-Schaffer F: Role of reactive oxygen species (ROS) in apoptosis induction. Apoptosis 5: 415-418, 2000.

8. Petronilli V, Penzo D, Scorrano L, Bernardi P and Di Lisa F: The mitochondrial permeability transition, release of cytochrome $c$ and cell death. Correlation with the duration of pore openings in situ. J Biol Chem 276: 12030-12034, 2001.

9. Han YW, Kim SZ, Kim SH and Park WH: The changes of intracellular $\mathrm{H}_{2} \mathrm{O}_{2}$ are an important factor maintaining mitochondria membrane potential of antimycin A-treated As4.1 juxtaglomerular cells. Biochem Pharmacol 73: 863-872, 2007.

10. King MA: Antimycin A-induced killing of HL-60 cells: apoptosis initiated from within mitochondria does not necessarily proceed via caspase 9. Cytometry A 63: 69-76, 2005.

11. Park WH, Han YW, Kim SW, Kim SH, Cho KW and Kim SZ: Antimycin A induces apoptosis in As4.1 juxtaglomerular cells. Cancer Lett 251: 68-77, 2007.

12. Han YH and Park WH: Growth inhibition in antimycin A-treated lung cancer Calu-6 cells via inducing a G1 phase arrest and apoptosis. Lung Cancer 65: 150-160, 2009.

13. Han YH and Park WH: Tiron, a ROS scavenger, protects human lung cancer Calu-6 cells against antimycin A-induced cell death. Oncol Rep 21: 253-261, 2009.

14. Blenis J: Signal transduction via the MAP kinases: proceed at your own RSK. Proc Natl Acad Sci USA 90: 5889-5892, 1993.

15. Genestra M: Oxyl radicals, redox-sensitive signalling cascades and antioxidants. Cell Signal 19: 1807-1819, 2007.

16. Kusuhara M, Takahashi E, Peterson TE, Abe J, Ishida M, Han J, Ulevitch $\mathrm{R}$ and Berk BC: p38 Kinase is a negative regulator of angiotensin II signal transduction in vascular smooth muscle cells: effects on $\mathrm{Na}+\mathrm{H}+$ exchange and ERK1/2. Circ Res 83: 824-831, 1998.

17. Hsin YH, Chen CF, Huang S, Shih TS, Lai PS and Chueh PJ: The apoptotic effect of nanosilver is mediated by a ROS- and JNK-dependent mechanism involving the mitochondrial pathway in NIH3T3 cells. Toxicol Lett 179: 130-139, 2008. 
18. Mao X, Yu CR, Li WH and Li WX: Induction of apoptosis by shikonin through a ROS/JNK-mediated process in $\mathrm{Bcr} /$ Abl-positive chronic myelogenous leukemia (CML) cells. Cell Res 18: 879-888, 2008

19. Guyton KZ, Liu Y, Gorospe M, Xu Q and Holbrook NJ: Activation of mitogen-activated protein kinase by $\mathrm{H}_{2} \mathrm{O}_{2}$. Role in cell survival following oxidant injury. J Biol Chem 271: 4138-4142, 1996.

20. Henson ES and Gibson SB: Surviving cell death through epidermal growth factor (EGF) signal transduction pathways: implications for cancer therapy. Cell Signal 18: 2089-2097, 2006.

21. Bassenge E: Endothelial function in different organs. Prog Cardiovasc Dis 39: 209-228, 1996.

22. Park WH, Seol JG, Kim ES, Hyun JM, Jung CW, Lee CC, Kim BK and Lee YY: Arsenic trioxide-mediated growth inhibition in MC/CAR myeloma cells via cell cycle arrest in association with induction of cyclin-dependent kinase inhibitor, p21 and apoptosis. Cancer Res 60: 3065-3071, 2000.

23. Han YH, Kim SZ, Kim SH and Park WH: Arsenic trioxide inhibits the growth of Calu- 6 cells via inducing a G2 arrest of the cell cycle and apoptosis accompanied with the depletion of GSH. Cancer Lett 270: 40-55, 2008.

24. Han YH, Kim SZ, Kim SH and Park WH: Apoptosis in pyrogallol-treated Calu- 6 cells is correlated with the changes of intracellular GSH levels rather than ROS levels. Lung Cancer 59: 301-314, 2008.
25. Han YH, Kim SZ, Kim SH and Park WH: Arsenic trioxide inhibits growth of As4.1 juxtaglomerular cells via cell cycle arrest and caspase-independent apoptosis. Am J Physiol Renal Physiol 293: F511-F520, 2007.

26. Han YH, Kim SH, Kim SZ and Park WH: Caspase inhibitor decreases apoptosis in pyrogallol-treated lung cancer Calu-6 cells via the prevention of GSH depletion. Int J Oncol 33: 1099-10105, 2008.

27. Yang J, Liu X, Bhalla K, Kim CN, Ibrado AM, Cai J, Peng TI, Jones DP and Wang X: Prevention of apoptosis by Bcl-2: release of cytochrome c from mitochondria blocked. Science 275: 1129-1132, 1997.

28. Chen HM and Yan XJ: Antioxidant activities of agaro-oligosaccharides with different degrees of polymerization in cell-based system. Biochim Biophys Acta 1722: 103-111, 2005.

29. Rhee SG, Yang KS, Kang SW, Woo HA and Chang TS: Controlled elimination of intracellular $\mathrm{H}(2) \mathrm{O}(2)$ : regulation of peroxiredoxin, catalase, and glutathione peroxidase via posttranslational modification. Antioxid Redox Signal 7: 619-626, 2005.

30. Estrela JM, Ortega A and Obrador E: Glutathione in cancer biology and therapy. Crit Rev Clin Lab Sci 43: 143-181, 2006. 